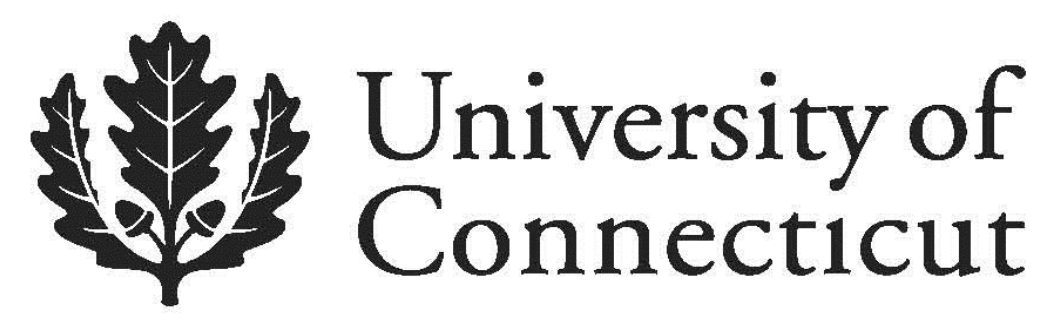

Department of Economics Working Paper Series

Regime Switching Model of US Crude Oil and Stock Market Prices:

1859 to 2013

Mehmet Balcilar

Eastern Mediterranean University

Rangan Gupta

University of Pretoria

Stephen M. Miller

University of Nevada-Las Vegas

University of Connecticut

Working Paper 2014-26

September 2014

365 Fairfield Way, Unit 1063

Storrs, CT 06269-1063

Phone: (860) 486-3022

Fax: (860) 486-4463

http://www.econ.uconn.edu/

This working paper is indexed on RePEc, http://repec.org 


\title{
Regime Switching Model of US Crude Oil and Stock Market Prices: \\ 1859 to 2013
}

\author{
Mehmet Balcilar \\ Department of Economics \\ Eastern Mediterranean University \\ Famagusta, NORTHERN CYPRUS, via Mersin 10, TURKEY \\ Rangan Gupta \\ Department of Economics \\ University of Pretoria \\ Pretoria, 0002, SOUTH AFRICA \\ Stephen M. Miller* \\ Department of Economics, \\ University of Nevada, Las Vegas \\ Las Vegas, Nevada, 89154-6005 USA \\ E-mail: stephen.miller@unlv.edu \\ Telephone: 01-702-895-3969 \\ Fax: 01-702-895-1354
}

\begin{abstract}
:
This paper examines the relationship between US crude oil and stock market prices, using a Markov-Switching vector error-correction model and a monthly data set from 1859 to 2013. The sample covers the entire modern era of the petroleum industry, which typically begins with the first drilled oil well in Titusville, Pennsylvania in 1858. We estimate a two regime model that divides the sample into high- and low-volatility regimes based on the variancecovariance matrix of the oil and stock prices. We find that the high-volatility regime more frequently exists prior to the Great Depression and after the 1973 oil price shock caused by the Organization of Petroleum Exporting Countries. The low-volatility regime occurs more frequently when the oil markets fell largely under the control of the major international oil companies from the end of the Great Depression to the first oil price shock in 1973. Using the National Bureau of Economic research business cycle dates, we also find that the highvolatility regime more likely occurs when the economy experiences a recession.
\end{abstract}

Keywords: $\quad$ Markov switching, vector error correction, oil and stock prices

JEL classification: $\quad$ C32, E37

* Corresponding author 


\section{Introduction}

Macroeconomic policymakers consider wealth as an important driver of the economy and view asset prices as important predictors of the business cycle. For example, researchers have long followed the stock market in the US as an important predictor of the business cycle. (Moore 1983; Siegel 1991; Chauvet 1998-1999). For example, Siegel (1991) determines that for the 41 recessions observed since 1802, at least an 8-percent loss in stock returns preceded 38. On the negative side, 12 false signals occurred using this criterion, where no recession followed. Seven of these false signals happened after WWII. Other researchers consider the predictive ability of crude oil prices. Hamilton $(2003,2009)$ argues that oil price shocks proximately cause post-WWII recessions in the US. ${ }^{1}$

The existing literature contains several attempts to identify the effects of changes in crude oil prices on certain macroeconomic variables, such as, real GDP growth rates, inflation, employment, and exchange rates (Hamilton, 1983; Gisser and Goodwin, 1986; Mork, 1989; Hooker, 1996; Davis and Haltiwanger, 2001, Hamilton and Herrera, 2002, Lee and Ni, 2002; Hooker, 2002, and so on). These research papers differ from each other and do not produce a general consensus.

Fewer research papers examine the relationship between crude oil prices and other asset prices, such as stock prices or stock returns. Market participants want a framework that identifies how oil-price changes affect stock prices or stock market returns. On theoretical grounds, oil-price shocks affect stock market returns or prices through their effect on expected earnings (Jones et al., 2004). The relevant literature includes the following studies. Kaul and Seyhun (1990) and Sadorsky (1999) report a negative effect of oil-price volatility

\footnotetext{
${ }^{1}$ Even other views exist, however. For example, Leamer (2007) argues that "housing is the business cycle," showing that significant declines in housing construction preceded 8 of the last 10 recessions. Iacoviello and Neri (2010) estimate a DSGE model and consider the role of the housing market in the propagation of the business cycle. They conclude that “... spillovers from the housing market to the broader economy are nonnegligible, concentrated on consumption rather than business investment, and have become more important over time, ...” (p. 57).
} 
on stock prices. Jones and Kaul (1996) show that international stock prices do react to oil price shocks. Huang et al. (1996) provide evidence in favor of causality effects from oil futures prices to stock prices. More recently, Faff and Brailsford (2000) report that oil-price risk proved equally important to market risk, in the Australian stock market. Hong et al. (2004) also identify a negative association between oil-price returns and stock-market returns. Pollet (2005) and Driesprong et al. (2008) find that oil-price changes predict stock market returns on a global basis, while Hammoudeh and Li (2004) and Hammoudeh and Eleisa (2004) also discover the importance of the oil factor for stock prices in certain oilexporting economies. Bittlingmayer (2005) documents that oil-price changes associate with war risk and those associated with other causes exhibit an asymmetric effect on the behavior of stock prices. Sawyer and Nandha (2006), however, using a hierarchical model of stock returns, report results against the importance of oil prices on aggregate stock returns, while they retain their explanatory power only on an industrial (sectoral) level. Finally, Gogineni (2008) also provides statistical support for a number of hypotheses, such as oil prices positively associate with stock prices, if oil price shocks reflect changes in aggregate demand, but negatively associate with stock prices, if they reflect changes in supply. Moreover, stock prices respond asymmetrically to changes in oil prices.

Recently, however, researchers began asking whether changes in macroeconomic variables cause oil price changes, leading to the decomposition of those oil price changes into the structural shocks hidden behind such changes (Kilian, 2008a; Kilian and Park, 2009). That is, different sources of oil price changes may imply non-uniform effects on certain macroeconomic variables. More specifically, the relevant literature generates mixed views regarding the effect of such oil-price shocks on asset prices, such as stock prices. Chen et al. (1986) argue that oil prices do not affect the trend of stock prices, while Jones and Kaul 
(1996) present evidence that favors a negative association. This negative relationship, however, does not receive support by Huang et al. (1996) and Wei (2003).

Kilian (2008a) criticizes all these analyses, because researchers treat oil-price shocks as exogenous. Certain work, however, argues that oil prices respond to factors that also affect stock prices (Barsky and Kilian 2002, 2004; Hamilton 2005; Kilian 2008b). Thus, researchers must decompose aggregate oil price shocks into the structural factors that reflect the endogenous character of such shocks.

Thus, this paper investigates the relationship between the Standard and Poor's S\&P 500 (SP500) stock market index and the West Texas Intermediate (WTI) spot crude oil price from September 1859 through December 2013, using a Markov-switching vector errorcorrection (MS-VEC) model. The MS-VEC model includes two regimes -- high- and lowvolatility regimes. One unique feature of our analysis is that the sample period runs from the beginning of the modern era of the petroleum industry with the drilling of the first oil well in the US at Titusville, Pennsylvania in 1958.

Our findings imply that the high-volatility regime more frequently existed prior to the Great Depression and after the 1973 oil price shock caused by the Organization of Petroleum Exporting Countries (OPEC). The low-volatility regime occurred more frequently during the period of time from the end of the Great Depression to the first OPEC oil price shock, where the oil markets fell largely under the control of the major international oil companies. We also find a proclivity for the high-volatility regime to occur when the economy experiences a recession.

The paper unfolds as follows. Section 2 outlines the methodology used in the analysis. Section 3 implements the several steps in estimating the MS-VEC - data description, unitroot tests, cointegration tests, MS-VEC estimation, calculation of smoothed probabilities of 
the high-volatility regime, and impulse response analysis -- and discusses the findings. Section 4 concludes.

\section{Methodology}

Conventional wisdom suggests that macroeconometric time-series models must address structural change and/or regime shift (see Granger, 1996). Indeed, the survey paper by Hansen (2001) or Perron (2006) affirm that econometric applications should distinctly consider regime shifts.

Econometricians recently developed new models that can tackle sufficiently certain types of structural changes. One appealing, the Markov switching (MS) approach proposed by Hamilton (1990) and later extended to multivariate time-series models by Krolzig (1997, 1999), can address structural breaks. Hamilton (1990) introduced univariate Markov switching autoregressive (MS-AR) model while Krolzig (1997, 1999) developed multivariate extensions to Markov switching vector autoregressive (MS-VAR) and Markov switching vector error correction (MS-VEC) models. The MS models fall within the category of nonlinear time-series models that emerge from nonlinear dynamic processes, such as highmoment structures, time-varying parameter, asymmetric cycles, and jumps or breaks in a time series (Fan and Yao, 2003). The long sample period includes several influential prior events, such as the Panic of 1907, the Great Depression, World War I and II, first and second OPEC oil-price shocks, and more recently the global financial crisis and Great Recession of 2008. The data also includes a significant number of influential business cycles. MS models can provide a good fit to such time series data with business cycles features and regime shifts.

Several studies successfully use MS models to analyze aggregate output and business cycles (e.g., Hamilton 1989; Diebold, et al. 1994; Durland and McCurdy 1994; Filardo 1994, Ghysels 1994; Kim and Yoo 1995; and Filardo and Gordon 1998). Numerous studies also utilize MS models in the context of stock market returns (e.g. Tyssedal and Tjostheim 1988; 
Schwert 1989; Pagan and Schwert 1990; Kim, et al. 1998; and Kim and Nelson, 1998). Following these studies, we consider the MS-VEC model, which, with its rich structure, can accommodate the dynamic features of oil and stock price data in our sample. The model choice unlike other traditional models not only efficiently captures the dynamics of the process in a co-integration space, but also possesses an appealing structural form and provides economically intuitive results.

The method chosen uses a vector-error correction (VEC) model with time-varying parameters where, given our objectives, the parameter time-variation directly reflects regime switching. In this approach, we treat changes in the regimes as random events governed by an exogenous Markov process, leading to the MS-VEC model. A latent Markov process determines the state of the economy, where the probability of the latent state process takes a certain value based on the sample information. In this model, inferences about the regimes reflects the estimated probability, which measures the probability of each observation in the sample coming from a particular regime. The MS-VEC model analyzes the time-varying dynamic relationship between the monthly spot crude oil and stock prices and extends the class of autoregressive models studied in Hamilton (1990) and Krishnamurthy and Rydén (1998). It also permits asymmetric (regime-dependent) inference for impulse response analysis. The structure of the MS-VEC model comes from the model studied in Krolzig (1997, 1999). Examples of these models, among others, include Psaradakis et al. (2004), Krolzig et al. (2002), and Francis and Owyang (2003). Our estimation approach uses the Bayesian Markov-chain Monte Carlo (MCMC) integration method of Gibbs sampling, from which we can calculate confidence intervals for the impulse response function of the MSVEC model. 
More specifically, let $F_{t}$ and $R_{t}$ denote the monthly spot crude oil and stock prices, respectively. ${ }^{2}$ Define the time-series vector $X_{t}$ up to and including period $t$ as $X_{t}=\left[F_{t}, R_{t}\right]^{\prime}$ and let $\mathfrak{J}_{t}=\left\{X_{\tau} \mid \tau=t, t-1, \ldots, 1-p\right)$, where $p$ is a nonnegative integer. For the vector valued time series $X_{t}$ of random variables, assume that a (probability) density function $f\left(X_{t} \mid \mathfrak{I}_{t-1}, \theta\right)$ exists for each $t \in\{1,2, \ldots, T\}$. We denote the parameters and the parameter space by $\theta$ and $\Theta$, respectively and denote the true value of $\theta$ by $\theta_{0} \in \Theta$. Let the stochastic variable $S_{t} \in\{1,2, \ldots, q\}$ follow a Markov (chain) process with $q$ states. In the MS-VEC model, the latent state variable $S_{t}$ determines the probability of a given state in the economy at any point in time. Noting that oil and stock prices are potentially cointegrated, but their dynamic interactions may exhibit time-varying parameters, ${ }^{3}$ our analysis uses the following MS-VEC model $^{4}$ :

$$
\Delta X_{t}=\mu_{S_{t}}+\sum_{k=1}^{p-1} \Gamma_{S_{t}}^{(k)} \Delta X_{t-k}+\Pi_{S_{t}} X_{t-1}+\varepsilon_{t}, \quad t=1,2, \ldots, T
$$

where $p$ is the order of the MS-VAR model, $\left[\varepsilon_{t} \mid S_{t} \sim N\left(0, \Omega_{S_{t}}\right)\right]$, and $\Omega_{S_{t}}$ is a $(2 \times 2)$ positive definite covariance matrix. The random state or regime variable $\boldsymbol{S}_{\boldsymbol{t}}$, conditional on $S_{t-1}$, is unobserved, independent of past $X s$, and assumed to follow a $q$-state Markov process. In other words, $\operatorname{Pr}\left[S_{t}=j \mid S_{t-1}=i, S_{t-2}=k_{2}, \ldots, \mathfrak{J}_{t-1}\right]=\operatorname{Pr}\left[S_{t}=j \mid S_{t-1}=i, \mathfrak{J}_{t-1}\right]=p_{i j}$, for all $t$ and $\boldsymbol{k}_{\boldsymbol{l}}$, regimes $i, j=1,2, \ldots, q$, and $l \geq 2$. More precisely, $S_{t}$ follows a $q$-state Markov process with transition probability matrix given by

\footnotetext{
${ }^{2}$ The oil and stock prices we analyze are all nonstationary time series as shown by the unit root tests given in Section 3. However, these oil and stock prices maintain a cointegration relationship, leading to the MS-VEC model.

${ }^{3}$ Several studies found that the dynamic links between the oil and stock prices are sensitive to sample period. Ciner (2001) finds strong linkage between oil prices and the stock market in the 1990s, but not in the 1970s and 1980s. Silvapulle and Moosa (1999) using daily data covering the period of 1985 - 1996 reported that their findings supports oil futures prices leading spot prices but more importantly there may be a changing pattern of leads and lags over the time period under considered.

${ }^{4}$ Camacho (2005) shows that the asymmetric dynamics of the equilibrium errors lead to the MS-VEC model.
} 


$$
P=\left[\begin{array}{cccc}
p_{11} & p_{12} & \cdots & p_{1 q} \\
\vdots & \vdots & & \vdots \\
p_{q 1} & p_{q 2} & \cdots & p_{q q}
\end{array}\right], \quad \sum_{j=1}^{q} p_{i j}=1
$$

Thus, $p_{i j}$ equals the probability of being in regime $j$ at time $t$, given that the economy was in regime $i$ at time $(t-1)$, where $i$ and $j$ take possible values in $\{1,2, \ldots, q\}$. This MS-VEC model allows all parameters, including the variance matrix $\Omega_{S_{t}}$, to depend on the latent regime or state variable $S_{t}$.

The $\Pi_{S_{t}}$ matrix contains the long-run relationships between the oil and stock prices in the MS-VEC model specified in equation (1). We can interpret switching $\Pi_{S_{t}}$ in three ways: switching in the cointegrating vectors $\left(\beta^{\prime}\right)$, the weighting matrix $(\alpha)$, or both. Although these approaches are de facto equivalent, our specification in the error-correction term implies a single set of long-run relationships and preserves the Engle-Granger notion of cointegration. We can write the long-run impact matrix $\Pi_{S_{t}}$ as follows:

$$
\Pi_{S_{t}}=\alpha_{S_{t}} \beta^{\prime}
$$

where $\Pi_{S_{t}}$ are the state-dependent, long-run impact matrices defined by the $(n \times r)$ matrix of the state-independent cointegrating vectors $\beta$ and the $(n \times r)$ state-dependent weighting matrix $\alpha_{S_{t}}{ }^{5}$ In other words, $\beta$ represents the coefficients of the long-run effects that do not change over the entire sample period and $\alpha_{S_{t}}$ stands for the regime-dependent adjustment coefficient that controls how the endogenous variables respond to the disequilibria represented by the $r$-dimensional vector $\beta^{\prime} X_{t-1}$. As such, the speed at which the variables adjust to the long-run equilibrium varies across regimes, which is a key distinction of the

\footnotetext{
${ }^{5}$ Following Krolzig (1997, 1999), we estimate the parameters in the cointegration vector $\beta$ using the Johansen (1988, 1991) method and imposing one cointegration relationship. These estimates enter the MS-VEC model as predetermined. Our specification assumes constant and regime independent cointegration vectors, while allowing for the presence of the regime-dependent adjustment to the equilibrium. This specification conforms with the nonlinear adjustment to equilibrium examined in Savit (1988).
} 
MS-VEC model in equations (1) to (3). For example, a shock in the oil price will exert a different effect on the stock price depending on whether the economy experiences a low or high volatility regime. In this model, due to the nonlinear dynamics of the equilibrium errors, ${ }^{6}$ denoted by $z_{t}=\beta^{\prime} X_{t-1}$, both the strength with which the equilibrium errors correct (i.e., $\alpha_{S_{t}}$ ) and the short-run dynamics of the endogenous variables (i.e., $\Gamma_{S_{t}}$ ) vary over time. In our specification, the switches capture differences across regimes in the rate of long-run adjustment.

In our paper, we assume that two regimes (i.e., $q=2$ ) will sufficiently describe the dynamic interactions between the oil and stock prices. That is, the two regimes model the crises-recovery (recession-expansion) cycles observed in many macroeconomic time series. A large number of studies show that a two-regime MS model proves rich enough to capture the regime switching behavior in macroeconomic time series (e.g., Hamilton 1988, 1989; Diebold, et al. 1994; Durland and McCurdy 1994; Filardo 1994, Ghysels 1994; Kim and Yoo 1995; and Filardo and Gordon 1998).

The MS-VEC model in equations (1) to (3) contains several satisfying properties for analyzing the short-run dynamic interactions of the variables and their responses to disequilibria. First, we can classify regimes as depending on the parameter switches in the full sample and, therefore, we can detect changes in dynamic interactions between the variables. Second, this model allows for many possible changes in the dynamic interactions between the variables at unknown periods. Third, we can make probabilistic inferences about the dates at which changes in regimes occur. We can evaluate whether a regime change actually occurs, and also identify the dates of such regime changes. Finally, we can also use

\footnotetext{
${ }^{6}$ Although the long-run parameters (i.e., $\beta$ ) are state-independent, Camacho (2005) shows that the equilibrium errors follow an MS-VAR model under specifications in equations (1) and (3). Indeed, equation (1) emerges from a model where the equilibrium errors follow an MS-VAR process.
} 
this model to drive regime dependent impulse response functions and to determine whether the effect of an oil price shock on the stock price varies with regimes.

The empirical procedure for building a suitable MS-VEC models starts with identifying a possible set of models to consider. We determine the order $p$ of the MS-VEC model using the Bayesian Information Criterion (BIC) in a linear $\operatorname{VAR}(p)$ model. The MSVEC model specifications may differ in terms of regime numbers $(q)$ and the variance matrix specification. We only consider regime-dependent (heteroskedastic) variance models, because both the oil and stock price series span a number of periods where volatilities vary significantly. Moreover, the actual variances of both oil and stock price series in the highvolatility regime exceed their respective variances in the low-volatility regime.

Once we identify a specific MS-VEC model, we next test for the presence of nonlinearities in the data. When testing the MS-VEC model against the linear VEC alternative, we follow Ang and Bekaert (2002) and use the likelihood-ratio statistic (LR), which is approximately $\chi^{2}(q)$ distributed with $q$ restrictions plus the nuisance parameters (i.e., free transition probabilities) that are not identified under the null. We use $p$-values based on the conventional $\chi^{2}$ distribution with $q$ degrees of freedom, while for the approximate upper bound for the significance level of the LR statistic, we use Davies (1987). If we establish nonlinearity, then we can choose the number of regimes and the type of the MS model based on both the likelihood-ratio statistic and the Akaike information Criterion (AIC). ${ }^{7}$

To estimate the MS-VEC model, we adopt a two-step procedure due to Krolzig (1997), Saikkonen (1992), Saikkonen and Luukkonen (1997), and Krolzig, et al. (2002). Since all variables in the MS-VEC model are stationary, the estimators are asymptotically normally distributed and the usual statistical inference applies (Krolzig, 1997; Saikkonen,

\footnotetext{
${ }^{7}$ Krolzig (1997) and Psaradakis and Spagnolo (2003) suggest selecting the number of regimes and the MS model using the AIC, and Psaradakis and Spagnolo (2003) show that using Monte Carlo experiment, the AIC generally yields better results in selecting the correct model.
} 
1992; Saikkonen and Luukkonen, 1997; Krolzig, et al., 2002). First, we determine the number of cointegrating relationships using the Johansen $(1988,1991)$ procedure. We obtain the equilibrium errors $z_{t}=\beta^{\prime} X_{t-1}$ in this first step. Second, we estimate the MS-VEC model using the $z_{t}$ determined in the first step. Saikkonen (1992) and Saikkonen and Luukkonen (1997) show that the Johansen procedure estimates the cointegrating vectors consistently, even in the presence of regime switching.

Three commonly used methods can estimate the parameters of the MS models. First, the maximum likelihood (ML), although the simplest method of estimation, proves computationally demanding and may exhibit slow convergence. ${ }^{8}$ The ML method faces two important practical difficulties. One, finding the global maximum of the likelihood function may prove difficult to locate. Two, the likelihood function for the important class of mixtures of normal distributions is not bounded and the ML estimator does not exist for the global maximum.

Second, the more commonly used method of estimation for the MS models is the expectation maximization (EM) algorithm (Dempster et al. 1977; Lindgren 1978; Hamilton 1990, 1994). Assuming a normal conditional distribution of $X_{t}$ given $\left\{\mathfrak{I}_{t}, S_{t}, S_{t-1}, \ldots, S_{0} ; \theta^{\prime}\right\}$, the likelihood function is numerically approximated using the EM algorithm in two steps. One, given the current parameter estimates and the data, we compute the conditional expectation of log likelihood (E-step), and two, we compute the parameters that maximize the complete-data log likelihood function (M-step). The EM algorithm may experience slow convergence and also we cannot directly compute the standard errors of the parameters from the EM algorithm.

Third, we can use the Bayesian MCMC parameter estimation based on the Gibbs sampling. The ML and EM methods usually fail for certain types of models, where we cannot

\footnotetext{
${ }^{8}$ Redner and Walker (1984) provide an excellent review of the ML estimation of the MS models.
} 
compute the full vector of likelihoods for each regime for each period. The MCMC works only with one sample path for the regimes rather than a weighted average of sample paths over all regimes and, therefore, avoids the problem faced by the ML and EM methods.

The MCMC indeed treats the regimes as distinct set of parameter. Our MCMC implementation uses the following steps: ${ }^{9}$ (i) Draw the model parameters given the regimes. In our case, transition probabilities do not enter this step. (ii) Draw the regimes given the transition probabilities and model parameters. (iii) Draw the transition probabilities given the regimes. In our case, model parameters do not enter this step.

First, we draw $\Omega_{S_{t}}$ given regimes, $P$, and $\eta_{S_{t}}=\left(\beta, \mu_{S_{t}}, \alpha_{S_{t}}, \Gamma_{S_{t}}\right)^{\prime}$ using a hierarchical prior. Our implementation draws a common covariance matrix from the Wishart distribution, given the inverse of the regime specific covariances. Then, we draw the regime specific covariances from the inverse Wishart distribution, given the common covariance. The degrees of freedom priors for Wishart and inverse Wishart distributions both equal 4. We use a flat prior and draw $\eta_{S_{t}}=\left(\beta, \mu_{S_{t}}, \alpha_{S_{t}}, \Gamma_{S_{t}}\right)^{\prime}$, given regimes, $P$, and $\Omega_{S_{t}}$ from a multivariate Normal distribution with 0 mean.

Second, we draw regimes $S_{t}$ given $\eta_{S_{t}}=\left(\beta, \mu_{S_{t}}, \alpha_{S_{t}}, \Gamma_{S_{t}}\right)^{\prime}, P$, and $\Omega_{S_{t}}$. This comes from the Bayes formula, where relative probability of regime $i$ at time $t$ equals the product of the unconditional regime probability times the likelihood of regime $i$ at time $t$. We draw regimes as a random index from $\{1, \ldots, q\}$, given relative probability weights. That is, we use the Forward Filter-Backwards Sampling (FFBS) (also called Multi Move Sapling) algorithm described in Chib (1996) to draw the regimes. Then, we reject any draw, if less than 5 percent of the observations fall in any of the regimes.

Finally, we draw unconditional probabilities $P$, given the regimes, from a Dirichlet distribution. We set the priors for the Dirichlet distribution as $80 \%$ probability of staying in

\footnotetext{
${ }^{9}$ See Fruehwirth-Schnatter (2006) for the details of the MCMC estimation of the MS models.
} 
the same regime and 20-percent probability of switching to the other regime. We perform the MCMC integration with 50,000 posterior draws with 20,000 burn-in draws.

We use the impulse response function (IRF) to analyze the dynamic interaction between the oil and stock price. The IRF analysis studies how a given shock in one variable propagates to all variables in the system over time (e.g., $h=1,2, \ldots, H$ steps after the shock hits the system). Computing multi-step IRFs from MS-VEC models as well as from all nonlinear time-series models prove complicated because no ordinary method of computing the future path of the regime process exists. The IRF analysis requires that we know the future path of the regime process, since the impulses depend on the system's regime in every time period.

Ideally, the IRFs of the MS-VEC model should integrate the regime history into the propagation period, which proves difficult to resolve. Two approaches work-around the history dependence of the IRFs in the MS models. Ehrmann et al. (2003) suggest assuming that regimes do not switch beyond the shock horizon, leading to regime-dependent IRFs (RDIRF). On the other hand, Krolzig (2006) acknowledges the historical dependence and allows the regime process to influence the propagation of the shocks for the period of interest, $h=1,2, \ldots H$. In Krolzig's approach, we compute the conditional probabilities of future regimes, $S_{t+h}$, given the regime $S_{t}$ and the transition probabilities, $P$.

One major attraction of the RDIRF analysis is the possibility of determining the time variation in the responses of variables to a particular shock. The RDIRF traces the expected path of the endogenous variable at time $t+h$ after a shock of given size to the $k$-th initial disturbance at time $t$, conditioned on regime $i$. The $k$-dimensional response vectors $\psi_{k i, 1, \ldots,}$ 
$\psi_{k i, h}$ represents a prediction of the response of the endogenous variables. (Ehrmann et al. 2003). We can define the RDIRFs as follows: ${ }^{10}$

$$
\psi_{k i, h}=\left.\frac{\partial E_{t} X_{t+h}}{\partial u_{k, t}}\right|_{S_{t}=\cdots=S_{t+h}=i} \text { for } h \geq 0
$$

where $\boldsymbol{u}_{\boldsymbol{k}, \boldsymbol{t}}$ denotes the structural shock to the $k$-th variable. In general, the reduced-form shocks $\varepsilon_{t}$ will correlate across the equations and $\varepsilon_{k, t}$ will not correspond to $\boldsymbol{u}_{\boldsymbol{k}, \boldsymbol{t}}$. This leads to the famous identification problem for which several solutions exist. We identify the structural shocks as $\varepsilon_{t}=F_{S_{t}} \boldsymbol{u}_{t}$. To make structural inferences from the data, we must identify the structural disturbances and, hence, $F$. In other words, we impose sufficient restrictions on the parameter estimates to derive a separate structural form for each regime, from which we compute the RDIRFs. As standard practice to measure the effect of the oil price on the stock price, we order the stock price last and use the recursive identification scheme (Sims 1980). The recursive identification scheme uses the Cholesky decomposition of the covariance matrix as $\Omega_{S_{t}}=L_{S_{t}} L_{S_{t}}^{\prime}$ and identifies structural shocks from $u_{t}=F_{S_{t}}^{-1} \varepsilon_{t}$ with $F_{S_{t}}=L_{S_{t}}$.

The RDIRF analysis, although simple to derive and to construct confidence intervals via bootstrap, is not appropriate, if regime switching likely occurs during the propagation of shocks. The Krolzig (2006) solution possesses appeal, but it cannot construct confidence intervals. In our study, we combine RDIRF analysis with MCMC integration. We examine whether the dynamic response of the stock price to oil price shocks depends on the state of the economy, such as crash or recovery periods, assuming a given regime (i.e., regime switching does occur during the shock propagation periods) and studying the propagation of the oil price shock in the future, which proves appropriate for our purposes. Building on the Bayesian impulse responses for the linear VAR models ( $\mathrm{Ni}$ et al. 2007), we drive the

\footnotetext{
${ }^{10}$ Refer to Ehrmann et al. (2003) for details on characteristics and computation of the regime-dependent impulse responses.
} 
posterior density of the RDIRFs from the Gibbs sampling. The simulations of the posteriors of the parameters jointly with the identification of the structural shocks via the Gibbs sampler directly yield the posterior densities of the RDIRFs. We compute the confidence bands by the MCMC integration with Gibbs sampling of 50,000 posterior draws with a burn-in of 20,000.

\section{Data and Empirical Findings}

\subsection{Data}

We collected data on the Standard and Poor's S\&P 500 (SP500) stock market index, and West Texas Intermediate (WTI) spot crude oil price from September 1859 through December 2013 for 1,852 observations. Data come from the Global Financial Database. We seasonally adjust the data using Census X13. Figure 1 plots the natural logarithm of the two series. The shaded (grey) bars identify the National Bureau of Economic Research (NBER) recessions in the US economy. Frequently, the SP500 and the WTI fall during recessions, although not in every recession.

Table 1 reports the descriptive statistics for the natural logarithms of the SP500 and WTI series in Panel A. Panel B gives the descriptive statistics for SP500 and WTI returns, measured as the logarithmic difference in the price series. In addition to the mean, standard deviation (SD), coefficient of variation (CV), minimum (min), maximum (max), skewness, and kurtosis statistics, the table reports the Jarque-Berra normality test (JB), the Ljung-Box first $[\mathrm{Q}(1)]$ and fourth $[\mathrm{Q}(4]$ autocorrelation tests, and the first $[\mathrm{ARCH}(1)]$ and fourth [ARCH(4)] order Lagrange multiplier (LM) tests for autoregressive conditional heteroskedasticity (ARCH).

For both series in logarithmic levels and logarithmic differences, we reject normality and find evidence of first- and fourth-order autocorrelation and autoregressive conditional heteroskedasticity. Using the coefficient of variation to measure relative volatility, we see 
that the WTI series exhibits more volatility than the SP500 in both logarithmic levels and logarithmic differences.

The oil price data go back to the first oil well drilled in the US on August 27, 1859 in Titusville, Pennsylvania, which typically defines the beginning of the modern era in the petroleum industry. ${ }^{11}$ The modern era began in the middle of the $19^{\text {th }}$ Century with the discovery of how to refine kerosene (and paraffin) from crude oil and the invention of the kerosene lamp. Kerosine replaced whale oil as the fuel of choice for lamps. The discovery by Edison of the first commercially practical incandescent light bulb in 1879 led to a phasing out of kerosene lamps. The invention of a commercially successful internal combustion engine in 1879 boosted the demand for gasoline and other petroleum distillates for transportation purposes. As we see from Figure 1, the early part of our sample sees boom and bust cycles in the WTI series. That is, crude oil production and demand experienced significant swings after the birth of the modern era.

As the petroleum industry matured, price wars amongst the major international companies in the 1920s led to the 1928 Achnacarry Agreement, which established the international petroleum cartel (Federal Trade Commission 1952). ${ }^{12}$ The Agreement divided markets, fixed prices, restricted production, and limited competition. The fixed prices supported the profitability of "high-cost" producers of petroleum and the market divisions and production restrictions attempted to prevent "low-cost" producers from lowering prices to expand their market shares. The world economy experienced the Great Depression shortly after the signing of the Achnacarry Agreement, leading to an 86-percent decline in the SP500

\footnotetext{
${ }^{11}$ The first oil well drilled goes back to the middle of the $4^{\text {th }}$ Century in China, using bamboo to drill and to form pipelines.

${ }^{12}$ As a precursor to the Achnacarry Agreement, non-US international oil companies signed the Red Line Agreement in 1914 that established the Turkish Petroleum Company (later the Iraq Petroleum Company) whereby these companies agreed not to participate in the crude oil markets in the Ottoman Empire except through the Turkish Petroleum Company. US international oil companies sought admission to this agreement in 1922, finally achieving entry in 1928.
} 
index from October 1929 through June 1932 and a 68-percent decline in the WTI price from January 1929 through May 1933. Figure 1 documents that the WTI price remained relatively stable from World War II until the effective emergence of OPEC in 1973. That is, although OPEC formed in 1960, They did not exert significant control over world crude oil prices until the countries in OPEC nationalized their domestic oil industry. Figure 1 also shows that the WTI price experiences much more volatility post-1973.

\subsection{Unit-root tests}

Table 2 Panel A reports unit-root tests for the log levels of the series with a constant and a linear trend in the test equation. Panel B reports unit-root tests for the first differences of the log series with only a constant in the test equation. ADF denotes the augmented DickeyFuller (Dickey and Fuller, 1979) test, $\mathrm{Z}_{\alpha}$, the Phillips-Perron $\mathrm{Z}_{\alpha}$ unit root test (Phillips and Perron, 1988), $\mathrm{MZ}_{\alpha}$ and $\mathrm{MZ}_{\mathrm{t}}$, the modified Phillips-Perron tests of Perron and $\mathrm{Ng}$ (1996), DF-GLS, the augmented Dickey Fuller test of Elliot et al. (1996) with generalized least squares (GLS) detrending, KPSS, the Kwiatkowski et al. (1992) stationarity test, and ZivotAndrews, the endogenous structural break unit root test of Zivot and Andrews (1992) with breaks in both the intercept and linear trend. $\mathrm{Z}_{\alpha}, \mathrm{MZ}_{\alpha}$, and $\mathrm{MZ}_{\mathrm{t}}$ tests depend on GLS detrending. For the ADF unit root statistic, we select the lag order by sequentially testing the significance of the last lag at the 10-percent significance level. We select the bandwidth or the lag order for the $\mathrm{MZ}_{\alpha}, \mathrm{MZ}_{\mathrm{t}}$, DF-GLS, and KPSS tests using the modified Bayesian Information Criterion (BIC)-based data dependent method of Ng and Perron (2001).

In Panel A of Table 2, the KPSS test rejects the null hypothesis of stationary series. All the other tests cannot reject the null hypothesis of nonstationary series. In Panel B, the KPSS test cannot reject the null hypothesis of stationary series whereas all other tests reject the null hypothesis of nonstationary series. In sum, all series test as first-difference stationary 
series. In sum, we conclude that both the SP500 and WTI series are nonstationary in their logarithmic differences.

\section{3. $\quad$ Multiple cointegration tests}

Table 3 reports selection criteria and multivariate cointegration tests for the VAR(p) model of the natural logarithms of SP500 and WTC. Panel A reports the AIC, BIC, and Hannan-Quinn (HQ) information criteria. The VAR order of 2 comes from the minimum BIC value. Panel B reports maximum eigenvalue $\left(\lambda_{\max }\right)$ and trace $\left(\lambda_{\text {trace }}\right)$ cointegration order tests of Johansen (1988, 1991). Both the maximum eigenvalue and trace tests support cointegration between SP500 and WTI. Panel C reports the multivariate cointegration test of Stock and Watson (1988). Under the null $q(k, k-r)$ of Stock-Watson cointegration test, we test $k$ common stochastic trends against $k-r$ common stochastic trends (or r cointegration relationships). We find support for cointegration between SP500 and WTI, using the Stock-Watson test.

\subsection{Estimation of MS-VEC model}

Table 4 reports estimation results and model selection criteria for the MS-VEC model given in equations (1) to (3). We select the lag order by the minimum BIC value in a VAR in levels as 2 for both linear VEC and MS-VEC models. We estimate the MS-VEC model using Bayesian Monte Carlo Markov Chain (MCMC) method with Gibbs sampling. The MCMC estimates employ 20,000 burn-in and 50,000 posterior draws. All reported estimates in the Table for the MS-VEC model come from the Bayesian estimation.

The likelihood ratio statistic tests the linear VEC model under the null against the alternative MS-VEC model. The LR test is nonstandard, since unidentified parameters exist under the null. The $\chi^{2}$ p-values (in square brackets) with degrees of freedom equal to the number of restrictions as well as the number of restrictions plus the numbers of parameters unidentified under the null reject the null of linearity. The p-value of the Davies (1987) test 
also rejects linearity. We estimate these models over the full sample period 1959:12-2012:12 with 1849 observations.

The long-run average probabilities of a low and high-volatility regime equal 0.72 and 0.28, respectively. That is, for our 1849 observations, we expect the low- (high-) volatility regime to occur on 1,334 (515) occasions. These numbers imply an average duration in the low (high-) volatility regime of 20.7 (8.0) months. The actual outcomes over our sample in the low- (high-) volatility regime equal 1,279 (570).

\subsection{Smoothed probabilities}

Figures 2 and 3 plot the estimates of the smoothed probabilities of high volatility regime (regime 2) of the MS-VEC model given in equations (1) to (3). The smoothed probabilities equal the means of the 50,000 posterior draws for each time period based on the FFBS algorithm.

In Figure 2, the shaded (grey) bars correspond the periods where smoothed probability of the high volatility regime equals or exceeds 0.5 . We note that the high volatility region occurs much more frequently in the pre-1990 era, during the Great Depression, and in the post 1973 period. Since recessions occur more frequently during the pre-1990 period, Figure 3 also plots the smoothed probability in regime 2 along with shaded (grey) bars that correspond to NBER business cycle recession. Visually, Figure 3 seems to show that a high smoothed probability of a high volatility region associates with a recession, although not all recessions associate with a high smoothed probability of a high volatility region. We calculated the average probability of the high volatility region during recessions and expansions, finding values of 0.49 and 0.28 .

If we define high- and low-volatility regimes as 1 and 0 , respectively, and recessions and expansions as 1 and 0 , respectively, then we can form a contingency table of outcomes. Table 5 reports the findings for the entire sample period of 1,849 observations. We soundly 
reject the $\chi^{2}$ test for independence, which equals 131.45 . The odds ratio implies that the economy is three times more likely to experience a recession in the high-volatility regime than in the low-volatility regime. In sum, we find a significant relationship between recessions and a high smoothed probability of the high volatility region

\subsection{Impulse response functions}

Figure 4 reports 1 to 20 step impulse responses of the stock price to a 1 standard deviation shock in the oil price. All impulses use the Cholesky factor orthogonalization. Impulses responses appear as solid lines and the 95-percent confidence intervals appear as dotted lines. The confidence intervals for the linear VEC model come from 1,000 bootstrap resampling. The MS-VEC impulse responses are computed using the regime dependent impulse response method suggested by Ehrmann et al. (2003). The confidence intervals for the MS-VEC models come from the 50,000 posterior draws.

The impulse responses for the linear VEC model show a significant positive effect of the oil price shock on the stock price. That is, a positive oil price shock of 1-percent leads to a growing positive movement in the stock price over time. On the other hand, the impulse responses during the low- and high-volatility regions show no significant effect and a significant negative effect, respectively.

Kilian and Park (2009) argue that the linkage between oil and stock prices depends on the shocks in the oil market. More specifically, shocks to global aggregate demand and shocks to precautionary demand lead to opposite effects on stock prices. ${ }^{13}$ That is, an unanticipated increase in global demand will raise both oil and stock prices whereas an increase in precautionary demand will lead to a jump in the oil price and a drop in the stock price, because uncertainty about future oil supply drives precautionary demand.

\footnotetext{
${ }^{13}$ Kilian and Park (2009) also argue that shocks to oil production prove the least important for explaining stock price movements.
} 
Our findings point to the importance of conditioning the linkages on the low- and high-volatility environments. When we do not differentiate, we find a positive response of stock prices to a positive shock to oil prices. When we condition on low- and high-volatility regimes, we find no relationship between the oil price shock and stock prices in the low volatility regime, supporting the findings of Huang et al. (1996) and Wei (2003), and a negative relationship for the high-volatility regime, supporting the findings of Jones and Kaul (1996).

\section{Conclusion:}

This paper examines the relationship between US crude oil and stock market prices, using a MS-VEC model and a monthly data set from 1859 to 2013. Our sample period begins at the time usually identified as the modern era of the petroleum industry, which links to the drilling of the first oil well in the US at Titusville, Pennsylvania in 1858 . The early part of the $20^{\text {th }}$ century saw the major international oil companies capturing control of the pricing of crude oil, This control continued until OPEC established its dominance with the nationalization of domestic oil industries in OPEC countries. That effect control by OPEC saw its initial success in the first oil price shock of 1973. Since then, OPEC's power waxed and waned over time.

We find that the natural logarithms of SP500 stock market index and the WTI crude oil price series exhibit non-stationary behavior. Moreover, these two series prove cointegrated, leading to our estimation of the MS-VEC model. We find that the highvolatility regime more frequently exists prior to the Great Depression and after the 1973 oil price shock caused by the OPECs. The low-volatility regime occurs more frequently during the period of time from the end of the Great Depression to the first OPEC oil price shock, where the oil markets fell largely under the control of the major international oil companies. 
The impulse-response function analysis in our non-linear model determines that an oil price shock delivers a negative effect on stock prices for the high-volatility economy, whereas no relationship exists for the low-volatility economy. Similar analysis in a linear model produces the opposite finding of a significant positive effect of an oil price shock on the stock price. This finding suggests that not accounting for nonlinearity can lead to problematic results. Moreover, the analysis of the linkages between oil and stock prices in the existing literature does not consider the long sample of observations in our paper, beginning with the modern era of the petroleum industry through the present. Our analysis opens the door for additional detailed analysis of the issues across this longer time horizon.

Finally, using the NBER business cycle dates, we examine the relationship between the smoothed probability of a high-volatility regime and a recession in the macroeconomy. We find it more likely that the high-volatility regime occurs when the economy experiences a recession.

\section{References}

Andrews, D. W. K., 1991. Heteroskedasticity and autocorrelation consistent covariance matrix estimation. Econometrica 59, 817-858.

Ang, A., Bekaert, G., 2002. International asset allocation with regime shifts. Review of Financial Studies 15, 1137-1187.

Barsky, R. B., Kilian, L., 2002. Do we really know that oil caused the great stagflation? A monetary alternative. NBER Macroeconomics Annual 2001, 137-183.

Barsky, R. B., Kilian, L., 2004. Oil and the macroeconomy since the 1970s. Journal of Economic Perspectives 18, 115-134.

Bittlingmayer, G., 2005. Oil and stocks: Is it war risk? Working Paper Series. University of Kansas.

Camacho, M., 2005. Markov-switching stochastic trends and economic fluctuations. Journal of Economic Dynamics \& Control 29, 135-158.

Chauvet. M., (1998-1999). Stock market fluctuations and the business cycle. Journal of Economic and Social Measurement 25, 235-257. 
Chib, S., 1996. Calculating posterior distributions and modal estimates in Markov mixture models. Journal of Econometrics 75, 79-97.

Ciner, C., 2001. Energy shocks and financial markets: nonlinear linkages. Studies in Nonlinear Dynamics \& Econometrics 5, 203-212.

Davies, R. B., 1987. Hypothesis testing when a nuisance parameter is present only under the alternative. Biometrika 74, 33-43.

Dempster, A. P., Laird, N. M., Rubin, D. B., 1977. Maximum likelihood from incomplete data via the EM algorithm. Journal of the Royal Statistical Society Series B 34, 1-38.

Dickey, D. A., Fuller, W. A., 1979. Distribution of the estimators for autoregressive time series with a unit root. Journal of the American Statistical Association 74, 427-431.

Diebold, F. X., Lee, J.-H., Weinbach, G. C., 1994. Regime switching with time-varying transition probabilities. In C. Hargreaves (ed.) Nonstationary Time Series Analysis and Cointegration, pp. 283-302, Oxford: Oxford University Press.

Driesprong, G., Jacobsen, B., Benjiman, M., 2008. Striking oil: Another puzzle? Journal of Financial Economics 89, 307-327

Durland, J. M., McCurdy, T. H., 1994. Duration-dependent transitions in a Markov model of U.S. GNP growth. Journal of Business and Economic Statistics 12, 279-288.

Ehrmann, M., Ellison, M., Valla, N., 2003. Regime-dependent impulse response functions in a Markov-switching vector autoregression model. Economics Letters 78, 295-299.

Elliott, G., Rothenberg, T. J., Stock, J. H., 1996. Efficient tests for an autoregressive unit root. Econometrica 64, 813-836.

Faff, R., Brailsford, T., 2000. A test of a two-factor 'market and oil' pricing model. Pacific Accounting Review 12 (1), 61-77.

Fan, J. Yao, Q., 2003. Nonlinear Time Series: NonparametrPsaric and Parametric Methods. New York: Springer.

Federal Trade Commission, 1952. The International Petroleum Cartel. Staff Report, submitted to Subcommittee on Monopoly, Select Committee on Small Business, US Senate, $82^{\text {nd }}$ Congress, $2^{\text {nd }}$ session. Washington, DC: U.S. Government Printing Office.

Filardo, A. J., 1994. Business-cycle phases and their transitional dynamics. Journal of Business and Economic Statistics 12, 299-308.

Filardo, A. J., Gordon, S. F., 1998. Business cycle durations. Journal of Econometrics 85, 99-123. 
Francis, N., Owyang, M., 2003. Asymmetric common trends: An application of monetary policy in Markov-switching VECM. Federal Reserve Bank of St. Louis working paper 2003-001B.

Fruehwirth-Schnatter, S., 2006. Finite Mixture and Markov Switching Models. Statistics. Springer.

Ghysels, E,. 1994. On the periodic structure of the business cycle. Journal of Business and Economic Statistics 12, 289-298.

Gisser, M., Goodwin, T. H., 1986. Crude oil and the macroeconomy: Tests of some popular notions. Journal of Money, Credit and Banking 18, 95-103.

Gogineni, S., 2008. The stock market reaction to oil price changes. Working Paper. University of Oklahoma.

Granger, C. W. J., 1996. Can we improve the perceived quality of economic forecasts? Journal of Applied Econometrics 11, 455-473.

Hamilton, J. D., 1983. Oil and the macroeconomy since World War II. Journal of Political Economy 9, 228-248.

Hamilton, J. D., 1988. A neoclassical model of unemployment and the business cycle. Journal of Political Economy 96, 593-617.

Hamilton, J. D., 1989. A new approach to the economic analysis of nonstationary time series and the business cycle. Econometrica 57, 357-384.

Hamilton, J. D., 1990. Analysis of time series subject to changes in regime. Journal of Econometrics 45, 39-70.

Hamilton, J. D., 1994. Time Series Analysis. Princeton, NJ: Princeton University Press.

Hamilton, J. D., 2003. What Is an Oil Shock? Journal of Econometrics 113, 363-398.

Hamilton, J. D., 2005. Oil and the macroeconomy, In: Durlauf, S., Blume, L. (Eds.), The New Palgrave Dictionary of Economics, 2nd Edition. Macmillan, London.

Hamilton, J. D., 2009. Causes and Consequences of the Oil Shock of 2007-08. Brookings Papers on Economic Activity (Spring), 215-261.

Hamilton, J. D., Herrera, M. A., 2002. Oil shocks and aggregate macroeconomic behavior. Journal of Money, Credit and Banking 36, 265-286.

Hammoudeh, S., Li, H., 2004. The impact of the Asian crisis on the behavior of US and international petroleum prices. Energy Economics 26, 135-160.

Hammoudeh, S., Eleisa, E., 2004. Dynamic relationships among the GCC stock markets and the NYMEX oil prices. Contemporary Economic Policy 22, 250-269. 
Hansen, B. E., 2001. The new econometrics of structural change: dating breaks in U.S. labor productivity. The Journal of Economic Perspectives 15, 117-128.

Hong, H., Torous, W., Valkanov, R., 2004. Do industries lead the stock market? Gradual diffusion of information and cross-asset return predictability. Working Paper, Stanford University and UCLA.

Hooker, M. A., 1996. What happened to the oil-price macroeconomy relationship? Journal of Monetary Economics 38, 195-213.

Hooker, M. A., 2002. Are oil shocks inflationary? Asymmetric and nonlinear specifications versus changes in regime. Journal of Money, Credit and Banking 34, 540-561.

Huang, R. D., Masulis, R. W., Stoll, H. R., 1996. Energy shocks and financial markets. Journal of Futures Markets 16, 1-27.

Iacoviello M., Neri, S., (2010). Housing market spillovers: Evidence from an estimated DSGE model. American Economic Journal: Macroeconomics 2(2): 125-164.

Johansen, S., 1988. Statistical analysis of cointegration vectors. Journal of Economic Dynamics and Control 12, 231-254.

Johansen, S., 1991. Estimation and Hypothesis Testing of Cointegration Vectors in Gaussian Vector Autoregressive Models. Econometrica 59, 1551-1580.

Jones, C. M., Kaul, G., 1996. Oil and the stock markets. Journal of Finance 51, 463-491.

Jones, D. W., Leiby, P. N., Paik, I. K., 2004. Oil price shocks and the macroeconomy: What has been learned since 1996. Energy Journal 25, 1-32.

Kaul, G., Seyhun, N., 1990. Relative price variability, real shocks, and the stock market. Journal of Finance 45, 479-496.

Kilian, L., 2008a. Not all oil price shocks are alike: Disentangling demand and supply shocks in the crude oil market. American Economic Review 99, 1053-1069..

Kilian, L., 2008b. Exogenous oil supply shocks: How big are they and how much do they matter for the US economy? Review of Economics and Statistics 90, 216-240.

Kilian, L., Park, C., 2009. The impact of oil price shocks on the U.S. stock market. International Economic Review 50, 1267-1287.

Kim, C. J., Nelson, C. R., 1998. Business cycle turning points, a new coincident index, and tests of duration dependence based on a dynamic factor model with regime switching. Review of Economics and Statistics 80, 188-201.

Kim, C., Nelson, C. R., Startz, R., 1998. Testing for mean reversion in heteroskedastic data based on Gibbs-sampling-augmented randomization. Journal of Empirical Finance 5, 131-154. 
Kim, M.-J., Yoo, J.-S., 1995. New index of coincident indicators: A multivariate Markov switching factor model approach. Journal of Monetary Economics 36, 607- 630.

Krishnamurthy, V., Rydén, T., 1998. Consistent estimation of linear and non-linear autoregressive models with Markov regime. Journal of Time Series Analysis 19, 291307.

Krolzig, H.-M., 1997. Markov Switching Vector Autoregressions Modelling: Statistical Inference and Application to Business Cycle Analysis. Berlin: Springer.

Krolzig, H.-M., 1999. Statistical analysis of cointegrated VAR processes with Markovian regime shifts. Working Paper \# 1113, Computing in Economics and Finance 1999, Society for Computational Economics.

Krolzig, H.-M., 2006. Impulse response analysis in Markov switching vector autoregressive models. Economics Department, University of Kent. Keynes College.

Krolzig, H.-M., Marcellino, M., Mizon, G. E., 2002. A Markov-switching vector equilibrium correction model of the UK labor market. Empirical Economics 27, 233-254.

Kwiatkowski, D., Phillips, P., Schmidt, P., Shin, J., 1992. testing the null hypothesis of stationarity against the alternative of a unit root. Journal of Econometrics 54, 159178.

Leamer, E. E., (2007). Housing is the business cycle. In Housing, Housing Finance, and Monetary Policy, Economic Symposium Conference Proceedings, Kansas City Federal Reserve Bank, 149-233.

Lee, K., Ni, S., 2002. On the dynamic effects of oil shocks: A study using industry level data. Journal of Monetary Economics 49, 823-852.

Lindgren, G., 1978. Markov regime models for mixed distributions and switching regressions. Scandinavian Journal of Statistics 5, 81-91.

Moore, G. H., (1983). Security markets and business cycles. In Business Cycles, Inflation, and Forecasting, 2nd edition. (Ed.) Moore, G. H., NBER Book Series Studies in Business Cycles, 139-160.

Mork, K.A., 1989. Oil and the macroeconomy when prices go up and down: An extension of Hamilton's results. Journal of Political Economy 91, 740-744.

Ng, S., and Perron, P., 2001. Lag length selection and the construction of unit root tests with good size and power. Econometrica 69, 1519-1554.

Ni, S., Sun, D., Sun, X., 2007. Intrinsic Bayesian estimation of vector autoregression impulse responses. Journal of Business and Economic Statistics 25, 163-176.

Pagan, A. R., Schwert, G. W., 1990. Alternative models for conditional stock volatility. Journal of Econometrics 45, 267-90. 
Perron, P. (2006). Dealing with Structural Breaks. Palgrave Handbook of Econometrics 1, 278-352.

Perron, P., Ng, S., 1996. Useful modifications to unit root tests with dependent errors and their local asymptotic properties. Review of Economic Studies 63, 435-465.

Phillips, P., Perron, P. (1988). Testing for a unit root in time series regression. Biometrika, 75, 335-346.

Pollet, J. M., 2005. Predicting asset returns with expected oil price changes. Available at SSRN: http://ssrn.com/abstract=722201.

Psaradakis, Z., Sola, M., Spagnolo, F., 2004. On Markov error-correction models, with an application to stock prices and dividends. Journal of Applied Econometrics 19, 69-88.

Psaradakis, Z., Spagnolo, N., 2003. On The Determination Of The Number Of Regimes In Markov-Switching Autoregressive Models. Journal of Time Series Analysis 24, 237252.

Redner, R. A., Walker, H., 1984. Mixture densities, maximum likelihood and the EM algorithm. SIAM Review 26, 195-239.

Saikkonen, P., 1992. Estimation and testing of cointegrated systems by an autoregressive approximation. Econometric Theory 8, 1-27.

Saikkonen, P., Luukkonen, R., 1997. Testing cointegration in infinite order vector autoregressive processes. Journal of Econometrics 81, 93-126.

Savit, R., 1988. When random is not random: an introduction to chaos in market prices. The Journal of Futures Markets 8, 271-290.

Sawyer, K. R., Nandha, M., 2006. How oil moves stock prices. Available at SSRN: http://ssrn.com/abstract=910427.

Schwert, G. W., 1989. Business cycles, financial crises, and stock volatility. CarnegieRochester Conference Series on Public Policy 31, 83-126.

Siegel, J. J., (1991). The Behavior of Stock Returns around N.B.E.R. Turning Points: An Overview. Rodney L. White Center for Financial Research, Philadelphia, PA.

Silvapulle, P., Moosa, I., 1999. The relationship between spot and futures prices: evidence from the crude oil market. Journal of Futures Markets19, 175-193.

Sims, C., 1980. Macroeconomics and reality. Econometrica 48, 1-48.

Stock, J. H., Watson, M. W., 1988. Testing for common trends. Journal of the American Statistical Association 83, 1097-1107.

Tyssedal, J. S., Tjostheim, D., 1988. An autoregressive model with suddenly changing parameters and an application to stock market prices. Applied Statistics 37, 353-69. 
Wei, C., 2003. Energy, the stock market, and the putty-clay investment model. American Economic Review 93, 311-323.

Zivot, E., Andrews, W., 1992. Further evidence on the great crash, the oil price shock and the unit root hypothesis. Journal of Business and Economic Statistics 10, 251-270. 
Table 1. Descriptive statistics.

\begin{tabular}{lcc}
\hline & SP500 & WTI \\
\cline { 1 - 2 } Panel A: loq levels & & \\
Mean & 3.337 & 1.406 \\
SD & 1.91 & 1.317 \\
CV & 0.572 & 0.937 \\
Min & 0.352 & -2.303 \\
Max & 7.499 & 4.897 \\
Skewness & 0.742 & 0.714 \\
Kurtosis & -0.696 & -0.218 \\
JB & $207.398^{* * *}$ & $160.993^{* * *}$ \\
Q(1) & $1846.705^{* * *}$ & $1839.056^{* * *}$ \\
Q(4) & $7341.834^{* * *}$ & $7219.099^{* * *}$ \\
ARCH(1) & $1847.788^{* * *}$ & $1822.354^{* * *}$ \\
ARCH(4) & $1844.866^{* * *}$ & $1824.999^{* * *}$ \\
Panel B: log returns & & \\
Mean & 0.0038 & 0.0009 \\
SD & 0.0477 & 0.0903 \\
CV & 12.553 & 100.333 \\
Min & -0.3563 & -0.6931 \\
Max & 0.3524 & 0.7985 \\
Skewness & -0.5263 & -0.2415 \\
Kurtosis & 8.5802 & 13.2378 \\
JB & $5780.1050^{* * *}$ & $13569.2650^{* * * *}$ \\
Q(1) & $25.6756^{* * *}$ & $274.7002^{* * *}$ \\
Q(4) & $34.8562^{* * *}$ & $320.4884^{* * *}$ \\
ARCH(1) & $92.4441^{* * *}$ & $198.9482^{* * *}$ \\
ARCH(4) & $227.6214^{* * *}$ & $296.9623^{* * *}$ \\
& & \\
$N$ & 1,852 & 1,852 \\
\hline Not & & \\
\end{tabular}

Note: The table gives the descriptive statistics for Standard and Poor's S\&P 500 Stock Market Index (SP500), and West Texas Intermediate spot crude oil price (WTI). All values are in natural logarithms in Panel A. Panel B gives the descriptive statistics for log returns. The sample period covers Sep. 1859-Dec. 2013 with $n=1852$ observations. S.D. and C.V. denote standard deviation and coefficient of variation, respectively. In addition to the mean, standard deviation (S.D.), minimum (min), maximum (max), skewness, and kurtosis statistics, the table reports the Jarque-Berra normality test (JB), the Ljung-Box first $[Q(1)]$ and the fourth $[Q(4]$ autocorrelation tests, and the first $[\mathrm{ARCH}(1)]$ and the fourth $[\mathrm{ARCH}(4)]$ order Lagrange multiplier (LM) tests for the autoregressive conditional heteroskedasticity (ARCH). ${ }^{* * *},{ }^{* *}$ and ${ }^{*}$ represent significance at the $1 \%, 5 \%$, and $10 \%$ levels, respectively. 
Table 2. Unit root tests.

LnSP500

LnWTI

Panel A: Unit-root tests in levels

ADF
$Z_{\alpha}$
$M Z_{\alpha}$
$M Z_{t}$
DF-GLS
KPSS
Zivot-Andrews

-1.4167 [20]

$-1.8971[24]$

$-15.1120[1]$

$-15.8780[1]$

$-5.4095[1]$

$-4.0321[1]$

$-1.5121[1]$

$-1.2883[1]$

$-1.5097[1]$

$-1.2811[1]$

KPSS

$5071.3870^{* * *}[1]$

$816.0628^{* * *}$ [1]

$-1.4167[1]$

$-1.8971[1]$

\section{Panel B: Unit-root test in first differences}

$\begin{array}{lcc}\text { ADF } & -10.0940^{* * *}[19] & -12.8508^{* * *}[23] \\ \mathbf{Z}_{\alpha} & -534.3900^{* * *}[15] & -700.0900^{* * *}[21] \\ \mathbf{M Z}_{\alpha} & -43.5732^{* * *}[9] & -106118.0000^{* * *}[14] \\ \mathbf{M Z}_{\boldsymbol{t}} & -4.6579^{* * *}[9] & -230.3450^{* * *}[14] \\ \mathbf{D F - G L S} & -3.8396^{* * *}[9] & -12.7764^{* * *}[21] \\ \text { KPSS } & 0.1461[9] & 0.0039[20]\end{array}$

Note: Panel A reports unit roots tests for the log levels of the series with a constant and a linear trend in the test equation. Panel B report unit root test for the first differences of the log series with only a constant in the test equation. ADF is the augmented Dickey-Fuller (Dickey and Fuller, 1979) test, $Z_{\alpha}$ is the Phillips-Perron $Z_{\alpha}$ unit root test (Phillips and Perron, 1988), $M Z_{\alpha}$ and $M Z_{t}$ are the modified Phillips-Perron tests of Perron and Ng (1996), DF-GLS is the augmented Dickey Fuller test of Elliot et al. (1996) with generalized least squares (GLS) detrending, KPSS is the Kwiatkowski et al. (1992) stationarity test, and Zivot-Andrews is the endogenous structural break unit root test of Zivot and Andrews (1992) with breaks in both the intercept and linear trend. $Z_{\omega}, M Z_{\omega}$ and $M Z_{t}$ tests are based on GLS detrending. For the ADF unit root statistic the lag order is selected by sequentially testing the significance of the last lag at $10 \%$ significance level. The bandwidth or the lag order for the $M Z_{\alpha}, M Z_{t}$, DF-GLS, and KPSS tests are select using the modified Bayesian Information Criterion (BIC)-based data dependent method of Ng and Perron (2001). ${ }^{* * *},{ }^{* *}$ and ${ }^{*}$ represent significance at the $1 \%, 5 \%$, and $10 \%$ levels, respectively. 
Table 3. Multivariate cointegration tests.

\section{Panel A: VAR order-selection criteria}

\begin{tabular}{lccccccc} 
Lag $(\boldsymbol{p})$ & 1 & 2 & 3 & 4 & 6 & 8 & 10 \\
\cline { 2 - 7 } AIC & -10.9114 & -11.0840 & -11.0816 & -11.0843 & $\mathbf{- 1 1 . 0 8 3 3}$ & -11.0874 & -11.0854 \\
HQ & -10.9048 & $\mathbf{- 1 1 . 0 7 3 0}$ & -11.0661 & -11.0644 & -11.0590 & -11.0587 & -11.0523 \\
BIC & -10.8934 & $\mathbf{- 1 1 . 0 5 4 1}$ & -11.0396 & -11.0304 & -11.0174 & -11.0095 & -10.9956
\end{tabular}

Panel B: Johansen cointegration tests

Eigenvalues $\quad 0.0174 \quad 0.0001$

\begin{tabular}{cccccccc} 
& & \multicolumn{3}{c}{ Critical values } & & \multicolumn{2}{c}{ Cointegration vector } \\
\cline { 3 - 5 } $\mathbf{H}_{\mathbf{0}}$ & $\lambda_{\max }$ & $10 \%$ & $5 \%$ & $1 \%$ & & LSP & LOIL \\
\hline $\boldsymbol{r}=\mathbf{1}$ & 0.2600 & 6.5000 & 8.1800 & 11.6500 & & 1.0000 & 1.0000 \\
$\boldsymbol{r}=\mathbf{0}$ & $32.5100^{* * *}$ & 12.9100 & 14.9000 & 19.1900 & & -1.4970 & 0.9614
\end{tabular}

\begin{tabular}{|c|c|c|c|c|c|c|}
\hline \multirow[b]{2}{*}{$\mathbf{H}_{0}$} & \multirow[b]{2}{*}{$\lambda_{\text {trace }}$} & \multirow[b]{2}{*}{$10 \%$} & \multirow[b]{2}{*}{$5 \%$} & \multirow[b]{2}{*}{$1 \%$} & \multicolumn{2}{|c|}{ Loadings } \\
\hline & & & & & LSP & LOIL \\
\hline$r \leq 1$ & 0.2600 & 6.5000 & 8.1800 & 11.6500 & -0.0007 & 0.0002 \\
\hline$r=0$ & $32.7800^{* * *}$ & 15.6600 & 17.9500 & 23.5200 & 0.0102 & 0.0001 \\
\hline
\end{tabular}

\section{Panel C: Stock-Watson cointegration test}

\begin{tabular}{|c|c|c|c|}
\hline \multirow{2}{*}{$\begin{array}{c}\mathrm{H}_{0}: q(k, k-r) \\
q(2,0)\end{array}$} & \multirow{2}{*}{$\begin{array}{c}\text { Statistic } \\
-2.2493\end{array}$} & \multicolumn{2}{|c|}{ Critical values for $q(4,3)$} \\
\hline & & $1 \%$ & -24.1694 \\
\hline$q(2,1)$ & $-17.4298^{* *}$ & $5 \%$ & -17.4041 \\
\hline & & $10 \%$ & -14.0011 \\
\hline
\end{tabular}

Note: Table reports selection criteria and multivariate cointegration tests for the $\operatorname{VAR}(p)$ model of variables LSP, and LOIL. Panel A reports the AIC, BIC, and Hannan-Quinn (HQ) information criteria. The VAR order is selected based on minimum BIC and is 2. Panel B reports maximal eigenvalue $\left(\lambda_{\max }\right)$ and trace $\left(\lambda_{\text {trace }}\right)$ cointegration order tests of Johansen $(1988,1991)$. Non-rejection of $r=0$ for the Johansen tests implies no cointegration. Panel C reports the multivariate cointegration test of Stock and Watson (1988). Under the null $q(k, k-r)$ of Stock-Watson cointegration test, $k$ common stochastic trend is tested against $k-r$ common stochastic trend (or $r$ cointegration relationship). Rejection of $q(2,1)$ for the Stock-Watson test implies cointegration. ${ }^{* * * * * *}$ and ${ }^{*}$ represent significance at the $1 \%, 5 \%$, and $10 \%$ levels, respectively. 
Table 4. Estimation results for the MS-VEC model.

Model selection criteria

Log likelihood

\begin{tabular}{cc} 
MS(2)-VEC & Linear VEC(2) \\
\hline 12267.1548 & 4996.9223 \\
-13.2430 & -5.3974 \\
-13.2428 & -5.3974 \\
-13.1713 & -5.3765
\end{tabular}

LR linearity test

\begin{tabular}{cc} 
Statistic & $\boldsymbol{p}$-value \\
\hline 4207.5566 & $\chi^{2}(9)=[0.0000]^{* * *}$ \\
& $\chi^{2}(11)=[0.0000]^{* * *}$ \\
& Davies $=[0.0000]^{* * *}$
\end{tabular}

Transition probability matrix

$$
P=\left[\begin{array}{ll}
0.9518 & 0.1250 \\
0.0482 & 0.8750
\end{array}\right]
$$

\section{Regime properties}

Regime 1

\begin{tabular}{ccc} 
Probability & Observations & Duration (months) \\
\hline 0.7217 & 1334 & 20.7468 \\
0.2783 & 515 & 8.0000 \\
\hline
\end{tabular}

Note: Table reports estimation results and model selection criteria for the MS-VEC model given in equations (1) to (3). The lag order is selected by the BIC in a VAR in levels as 2 for both linear VEC and MS-VEC models. The MS-VEC model is estimated using Bayesian Monte Carlo Markov Chain (MCMC) method where we utilize Gibbs sampling. The MCMC estimates are based on 20.000 burn-in and 50.000 posterior draws. All reported estimates in the Table for the MS-VEC model are obtained from the Bayesian estimation. The likelihood ratio statistic tests the linear VEC model under the null against the alternative MS-VEC model. The test statistic is computed as the likelihood ratio (LR) test. The LR test is nonstandard since there are unidentified parameters under the null. The $\chi^{2} p$-values (in square brackets) with degrees of freedom equal to the number of restrictions as well as the number of restrictions plus the numbers of parameters unidentified under the null are given. Regime properties include ergodic probability of a regime (long-run average probabilities of the Markov process), observations falling in a regime based on regime probabilities, and average duration of a regime. The $p$-value of the Davies (1987) test is also given in square brackets. The models are estimated over the full sample period 1959:122012:12 with 1849 observations. ${ }^{* * *},{ }^{* *}$ and ${ }^{*}$ represent significance at the $1 \%$, 5\%, and $10 \%$ levels, respectively.

Table 5. High- and low-volatility versus recession and expansion outcomes.

\begin{tabular}{lccc}
\hline & High Volatility & Low Volatility & Count \\
\hline Recession & 288 & 302 & 590 \\
Expansion & 282 & 977 & 1259 \\
Count & 570 & 1279 & 1849 \\
\hline
\end{tabular}

Note: The high- (low-) volatility regime occurs when the smoothed probability of the high-volatility regime is greater than or equal to (less than) 0.5. Recessions and expansions depend on the NBER business cycle dates. 
Figure 1. Natural Logarithms of SP500 and WTI: Sept.1859-Dec. 2013

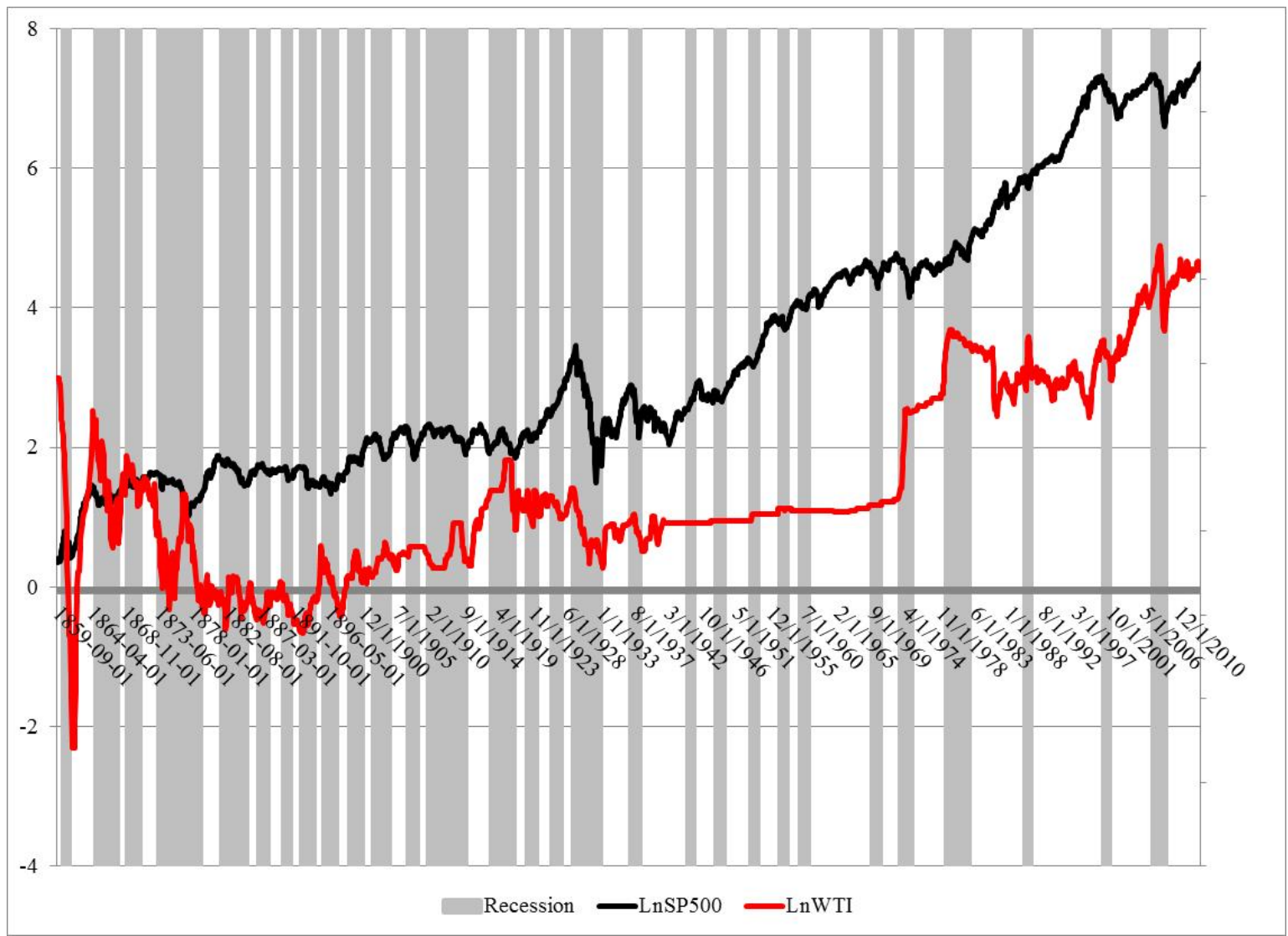


Figure 2. Smoothed probability estimates of high volatility (regime 2).

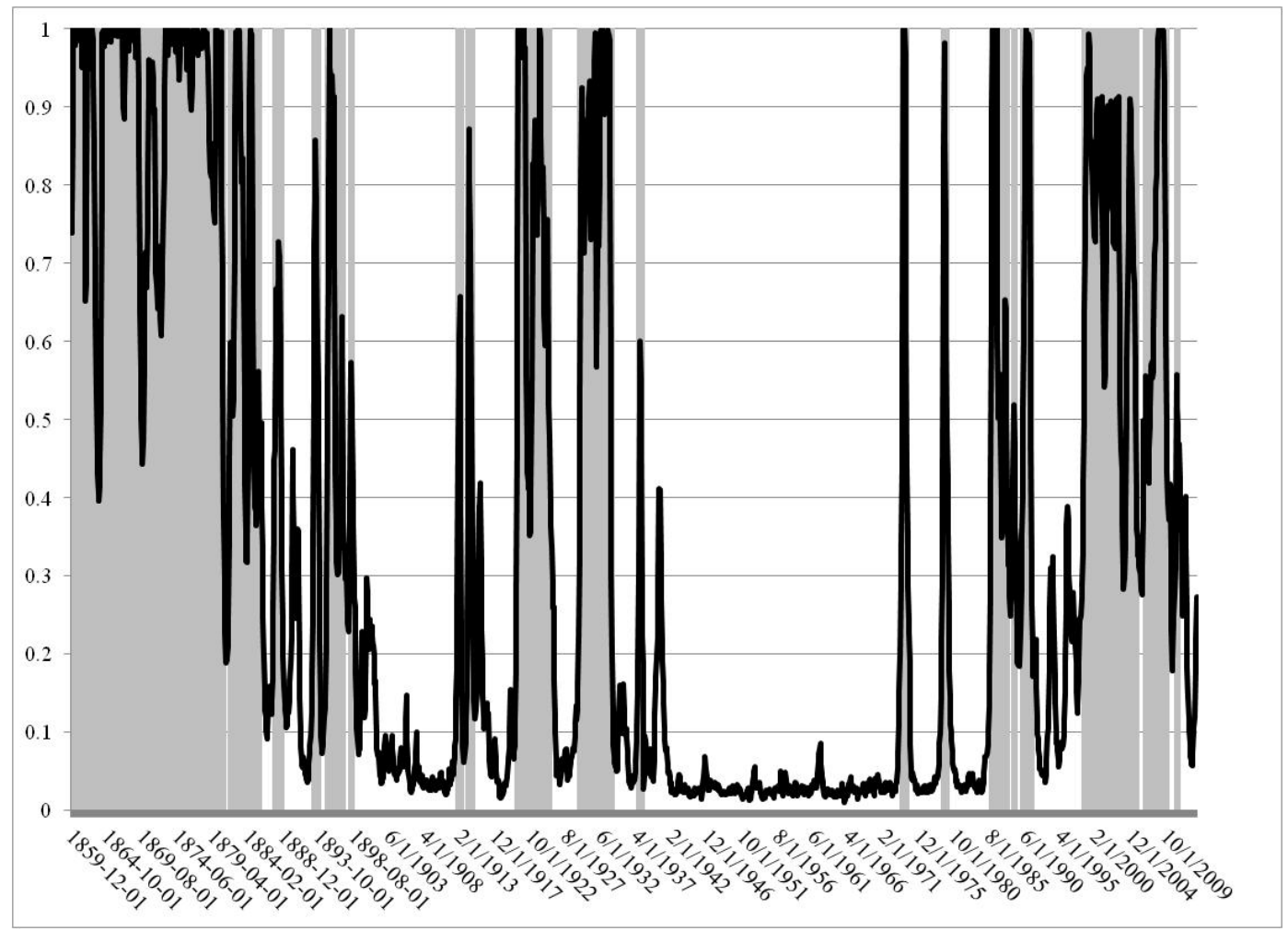

Figure 3. Smoothed probability estimates of high volatility (regime 2) and recessions.

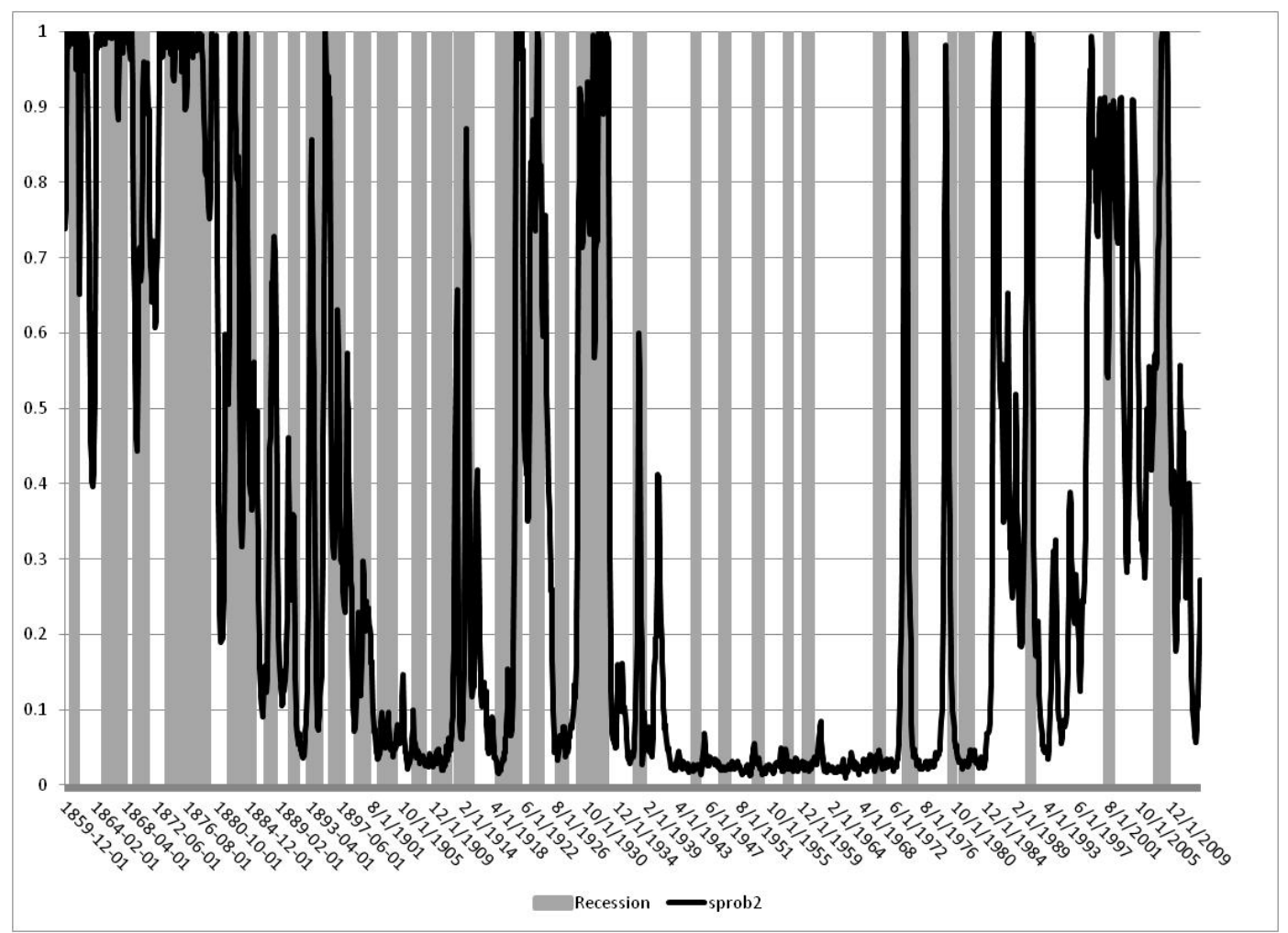


Figure 4. Impulse response of stock price to oil price in linear VEC and MS-VEC models.

a) Response of stock price to oil price shock in regime 1 of MS-VEC model

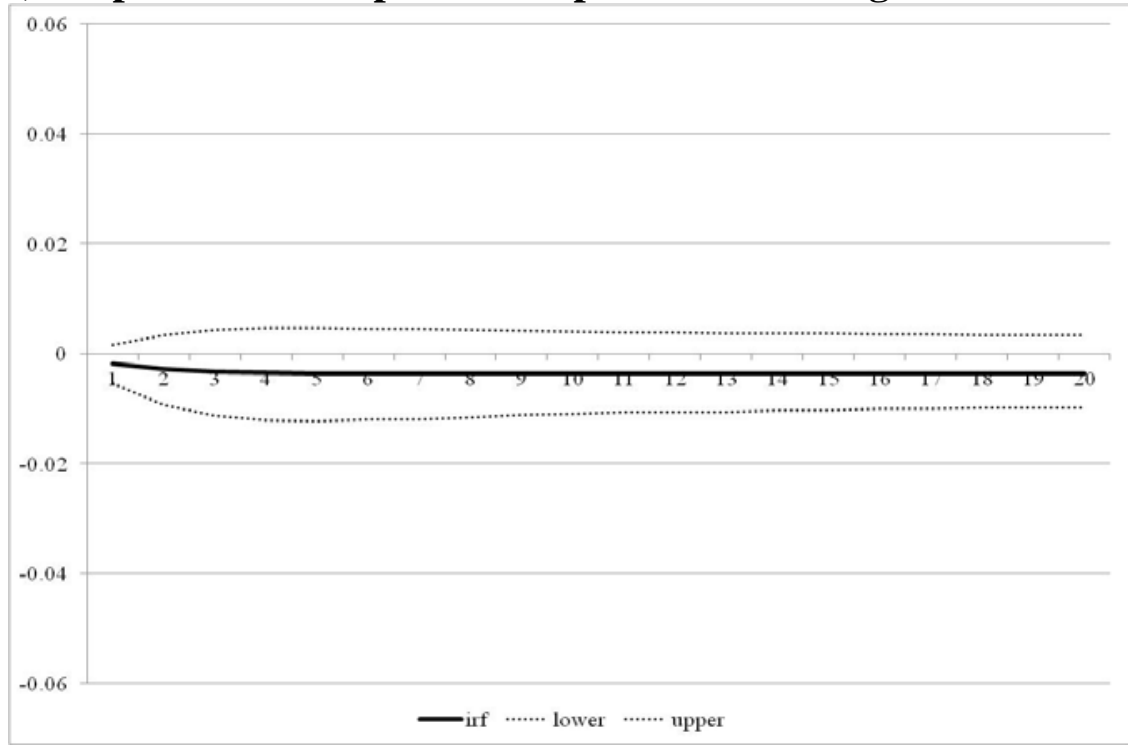

b) Response of stock price to oil price shock in regime 2 of MS-VEC model

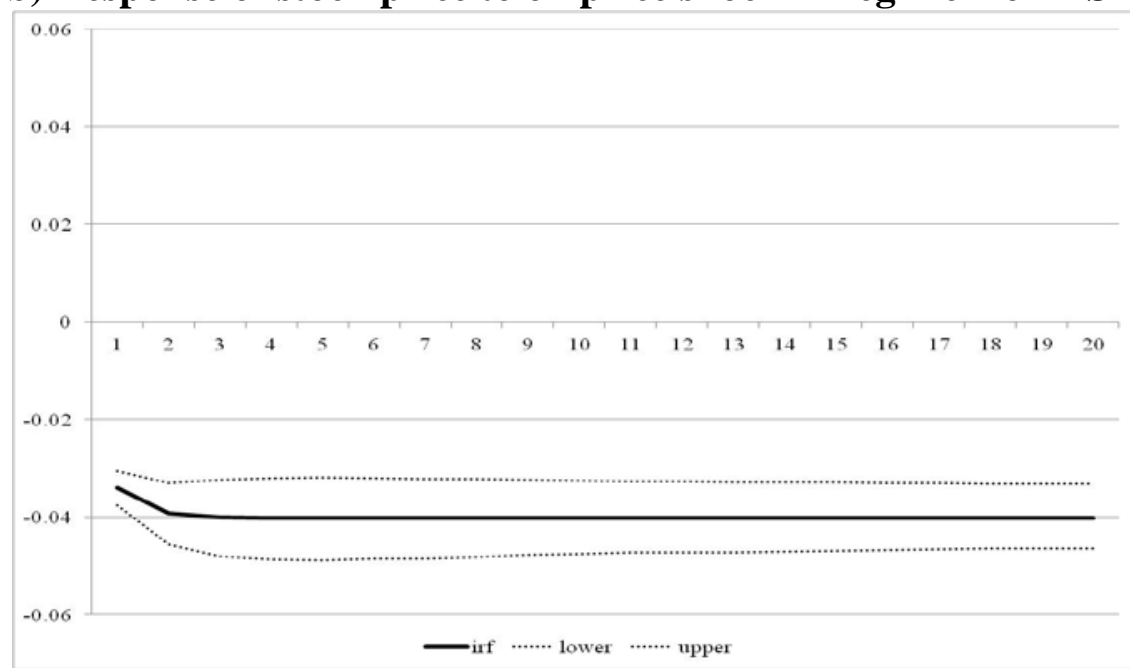

c) Response of stock price to oil price shock in linear VEC model

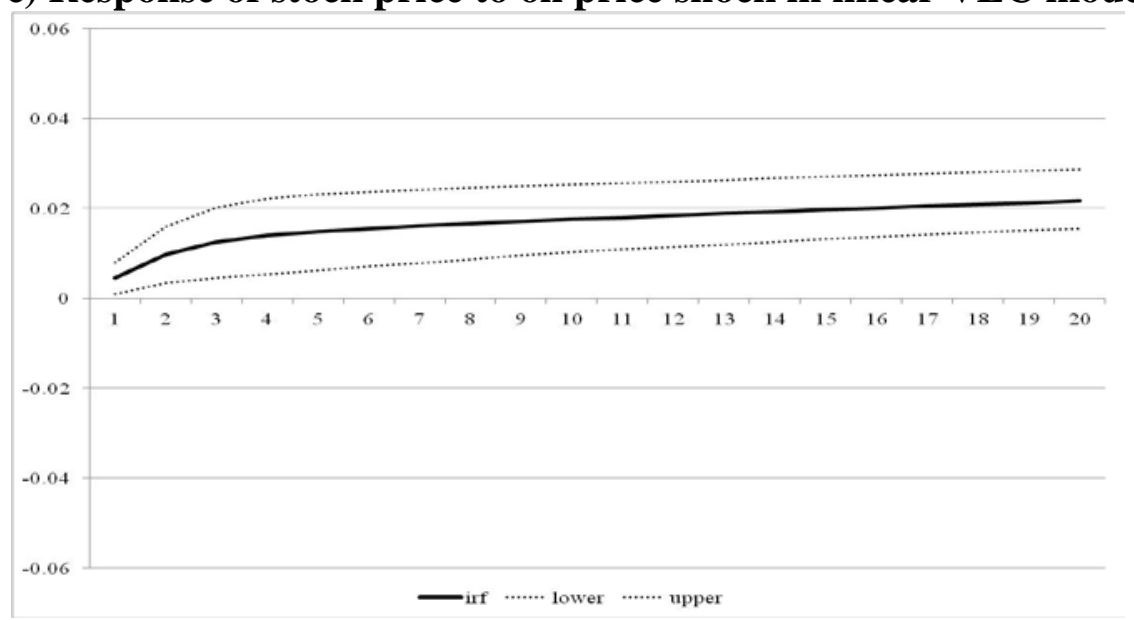

